\title{
Rememorando aspectos de vivências matemáticas
}

Idemar Vizolli*

R esumo: Esse artigo é parte da pesquisa que resultou em nossa tese de doutoramento, tendo como base teórica os registros de representação semiótica de D uval, enfatizando o modo como alunos e professores de um curso de E ducação de J ovens e A dultos solucionam problemas de proporção-porcentagem. Para desenvolver a pesquisa, foram realizados quatro estudos e neles foram realizadas entrevistas com os sujeitos. A presentamos recortes de vivências como aluno, professor e pesquisador em E ducação M atemática. Tais experiências indicam que as pessoas com pouca escolarização buscam referentes em situações do seu contexto social para solucionar problemas que envolvem conceitos matemáticos e apoiam seus raciocínios em situações matemáticas que lhes são conhecidas. É necessário que o processo de escolarização valorize e respeite os conhecimentos produzidos nos contextos culturais e os levem em consideração quando do processo de ensino e aprendizagem.

Palavras-chave: Problemas matemáticos, Conhecimentosmatemáticos, Processo de solução de problemas.

A bstract: This paper is part of the research that resulted in our doctoral dissertation, embased in the Duval semiotic representations registres, emphasizing theway how thestudents and teachers of an Adult and Youth E ducation (EJA) course solve proportion-

Professor Adjunto no Curso de L icenciatura em M atemática na U niversidade Federal do Tocantins, Campus de A rraias. D esenvolve pesquisas voltadas à E ducação M atemática, com ênfase em processos de ensino e aprendizagem, matemática em contextos socioculturais e na Educação de Jovens e Adultos. M estre em Educação pela U FSC e Doutor em Educação pela UFPR. E-mail: idemar@uft.edu.br 
percentage problems. To developde the research, it were realized four studies and in them were made interviews with the subjects. We present some clippings of life's experiences as student, teacher/ professor and $M$ athematical $E$ ducation researcher. These experiences indicate that the people with low education look for references in situations of thesocial context to solveproblems that involveM athematical concepts and they stand their reasonings in $M$ athematical situations which they know. I t's necessary that the scholling process valorize and respect the produced knolegdes in the cultural contexts considering then in the teaching-learning process.

K eywords: $M$ athematical problems, $M$ athematical knowledges, Problems solution process.

\section{Algumas palavras sobre nossas vivências matemáticas...}

U ma das formas de tematizar a realidade é buscar na história de vida elementos que nos instigam/intrigam, que nos despertam desejos ou frustrações, que resultam em problemas para os quais não temos solução e que talvez nem cheguemos a têla. De qualquer forma, são perguntas para as quais ainda não encontramos respostas ou mesmo curiosidades ainda não satisfeitas. Ao recorrer à história de vida, procuramos melhor compreender o processo pelo qual as pessoas solucionam problemas matemáticos com que se deparam em seu dia-a-dia.

\section{Como aluno}

Ao frequentar como aluno o MOBRAL, ${ }^{1}$ muitos dos problemas de matemática que eram propostos em sala de aula

1 M ovimento Brasileiro de Alfabetização - projeto do governo federal para erradicação do analfabetismo. 
referiam-se a questões do contexto imediato, como a compra e venda de produtos agrícolas, assunto familiar às pessoas adultas da região oeste do Estado de Santa Catarina onde morava, bem como, a várias outras regiões do país e do mundo. A relação utilitária da matemática é traço muito próprio do aprendiz adulto, conforme menciona Fonseca (2002).

M uitos dos colegas adultos sabiam resolver de cabeça os problemas que eram propostos, mesmo que não tivessem um amplo domínio conceitual das idéias e das relações matemáticas envolvidas no problema. De alguma forma, eles articulavam os conhecimentos matemáticos com outros saberes que lhes permitissem realizar seu trabalho. D e acordo com Giardinetto (1999), ao se inserir numa realidade, o homem cria e produz meios para garantir suas necessidades.

Para Franco (2000), ao lidar com o que precisam, os sujeitos podem desenvolver um pensamento operatório formal, sem necessariamente depender de uma vivência escolar. Ao se deparar com um problema prático ou simbólico, o sujeito busca uma forma de poder lidar operatoriamente com ele, e o resultado dessa operação se transforma novamente em conteúdo para ser expresso como solução do problema. A realidade imediata dos colegas exigia que efetuassem as operações matemáticas que Ihes permitissem calcular as despesas, os lucros ou os prejuízos, quando da comercialização de produtos. Para isso, inventavam estratégias para encontrar a resposta do problema.

As estratégias são concebidas como um conjunto de procedimentos que possibilitam atingir um determinado objetivo; neste caso, solucionar os problemas de matemática que eram propostos em sala de aula. De acordo com Polya (1975), trata-se de elaborar e de executar um plano de ações flexíveis que permitem encontrar elementos que possibilitam responder ao que é perguntado no enunciado do problema. Para Spinillo (1995), as estratégias refletem o modo de pensar e as relações que o sujeito estabelece acerca dos dados contidos em um problema. Analisar as estratégias é algo complexo, mas auxilia a compreender as noções que as pessoas apresentam e as dificuldades que experimentam na aquisição de conceitos matemáticos. 
Com o passar do tempo, e a partir dos diálogos com os colegas (trocando experiências e compartilhando estratégias), fomos aprendendo como proceder para organizar as informações earticular os dados contidos no problema, a fim de operar matematicamente. Já as pessoas que não dominavam o código da escrita matemática demonstravam interesse em conhecer a forma canônica de resolução, isto é, solucionar os problemas por meio da utilização de algoritmos. M as não é só isso. Ao frequentarem a escola, as pessoas adultas objetivam conhecer a matemática que lá é ensinada, compreender os conceitos matemáticos. D e acordo com Piconez (2002), há expectativa e esforço dos alunos para aceder ao conhecimento formal, ideia que também é compartilhada por Carvalho (1995) e Fonseca (2001; 2002).

Pensando na situação, hoje, parece-nos que os colegas haviam tomado consciência de que o cálculo mental Ihes era útil, mas não o suficiente para suprir as demandas criadas pelo contexto social. A creditávamos que esse era mais simples e menos trabaIhoso. H oje compreendemos que ocorriam duas realidades distintas, mas não desconexas: queríamos ressignificar o que fazíamos e solucionar os problemas que nos eram propostos. R essignificar o que fazíamos significava, para os colegas, atribuir um status aos cálculos, de forma que pudessem operar matematicamente, utilizando algoritmos convencionais, enquanto que nós queríamos compreender como operar com os dados e as informações disponibilizadas nos enunciados dos problemas. Cada um, a seu modo, objetivava compreender os conceitos matemáticos envolvidos no processo de solução dos problemas escolares que nos eram propostos, criando, procurando meios e "inventando" estratégias para enfrentar a realidade. O u, conforme aponta Silva (2002), desenvolvendo a capacidade operativa com a matemática, como consequência da compreensão das estruturas e ideias matemáticas e não da simples aplicação de algoritmos ou fórmulas.

Ao mesmo tempo em que apresentávamos diferenças em relação à forma de solucionar os problemas de matemática que nos eram propostos em sala de aula, entre nós, havia colaboração e respeito em relação aos saberes de que cada um dispunha. Queríamos acessar o conhecimento reconhecido pela sociedade. 
$\mathrm{N}$ a continuidade do processo de escolarização, fomos descobrindo formas para utilizar regras, macetes e fórmulas, embora não compreendêssemos o sentido daquilo que estávamos fazendo. N ão tivemos dificuldades em solucionar os problemas de matemática que eram propostos em sala de aula. Em outras palavras, o exercício do cálculo mental e a utilização de registros canônicos foram fundamentais para ingressar no mundo da matemática formal, embora o significado do trabalho que desenvolvíamos na escola só fizesse sentido para aquele tipo de exercício de matemática.

N em o cálculo mental, nem a matemática que nos foi passada na escola foram suficientes para compreender e dar significado aos conceitos matemáticos estudados. Foi preciso uma longa caminhada como professor, agora como pesquisador, para compreendermos alguns dos aspectos que hoje julgamos importantes ao processo de ensino e de aprendizagem da matemática: significá-la, para que os alunos passem a compreender o conceito do que estão estudando e o façam com sentido.

\section{Como professor}

$\mathrm{H}$ oje compreendemos que as regras, os macetes e as fórmulas decorrem de regularidades que são identificadas em situações matemáticas que possibilitam generalizações e abstrações. Estas nos conduzem ao resultado de uma operação matemática mais rapidamente.

M uitas vezes, a maneira como as pessoas solucionam problemas de matemática propostos em sala de aula é desconhecida por muitos professores, inclusive por aqueles que lecionam esta disciplina. A pelamos aqui para a responsabilidade social da escola, destacada por Silva (2002), principalmente no que consiste em habilitar os alunos para formular e resolver problemas matemáticos do contexto em que a escola está inserida, pois muitos de nós, professores, desconhecemos aspectos importantes da cultura que nos circunda. 
U ma das razões que leva muitas pessoas adultas a retornarem ao processo de escolarização, se não a principal, está relacionada às exigências do mercado de trabalho.

São, portanto, os próprios trabalhadores que, diante das necessidades novas, passam a buscar a escolaridade como possibilidade de acesso e permanências no emprego, ascensão profissional, melhoria de seus salários e condições de vida, bem como outros interesses (SANTA CATAR IN A, 2005, p. 120).

Carvalho (1995) destaca que pessoas com pouca escolarização, que sabem solucionar alguns dos problemas de seu contexto social imediato, ${ }^{2}$ não veem relação do que fazem com os conhecimentos matemáticos de que necessitam para ter sucesso na escola. Isso nos permite dizer que pessoas escolarizadas, inclusive os professores que ensinam matemática, não conhecem, por exemplo, como os pescadores efetuam o sistema de rateio do valor monetário do pescado, como os agricultores efetuam a cubagem de terra ou de madeira. M esmo quando conhecem, possuem dificuldades em identificar a relação entre os conhecimentos matemáticos implicados na solução dos problemas e o saber escolar de matemática. $\mathrm{E}$, ainda que consigam, dificilmente reconhecem a relevância de estabelecer essa relação para o aprendizado da estratégia escolar e, mais, para ampliá-la e aprimorá-la (ao invés de mera substituição).

A lém de saber como as pessoas adultas solucionam problemas de matemática em seu contexto social imediato, é importante que os professores de matemática identifiquem os conhecimentos matemáticos não-escolares apresentados nessas soluções. Acreditamos que, se os professores identificarem os diferentes registros de representação semiótica (DUVAL, 1993) como

2 U tilizamos a expressão "contexto social imediato" para falar do contexto em que as pessoas vivem: a rua, o bairro, a cidade, o comércio, a profissão que exercem, o trabalho que realizam, as atividades que desenvolvem em seu dia-a-dia, sem perder de vista que este contexto sofre influências e influencia as políticas do contexto social mais amplo (Estado, país e mundo). 
ponto de partida e de ancoragem para a proposição e de desenvolvimento de atividades, auxiliarão seus alunos a ampliarem os conhecimentos que já possuem.

Tanto a fala como a escrita dos cálculos em papel podem fornecer elementos que permitam aos professores saber como os alunos organizam e tratam as informações contidas no enunciado de um problema. Fonseca refere-se à habilidade matemática, considerando-a como

capacidade de mobilização de conhecimentos associados à quantificação, à ordenação, à orientação e as suas relações, operações erepresentações, na realização detarefas ou na resolução de situaç̃ões-problema, tendo sempre como referência tarefas e situações com as quais a maior parte da população brasileira se depara cotidianamente (2004, p. 13).

O conhecimento sistematizado de que já dispúnhamos, aliado às experiências de 16 anos de magistério, permitiram-nos dar os primeiros passos a fim de (re)pensar nossa relação com a matemática, no papel de professor desta disciplina. I nicialmente, como um instrumento que pudesse contribuir com os alunos e Ihes trazer perspectivas de melhorias nas condições de aprendizagem; mas o de que dispúnhamos era insuficiente para tanto. Para nós, o problema não estava nos alunos, mas sim na forma como a matemática Ihes era ensinada. É como nos diz Freire, não se começa a ser professor "numa certa terça-feira às quatro horas da tarde" (1991, p. 58).

N os últimos anos, temos voltado nosso olhar para o ensino da matemática na EJA, mais especificamente em saber como pessoas sem escolarização ou pouco escolarizadas solucionam problemas de matemática em seu contexto social imediato e as estratégias que utilizam para solucionar os problemas que lhes são propostos.

Ao atuar na formação continuada de professores do curso de EJA que ensinam matemática, percebemos que os professores dificilmente conseguem perceber que um dado conceito matemático interconecta-se a outros conceitos eque existem diferentes sistemas de registros possíveis de serem utilizados para 
representar um dado objeto matemático. Percebemos, também, que os professores, assim como muitos dos alunos, fazem uso de estratégias ou de procedimentos usuais no contexto social imediato para solucionar problemas de matemática propostos em sala de aula.

Esse panorama indica que é preciso estudar com os professores teorias e metodologias que fundamentem sua ação, de forma a melhorar o processo ensino e aprendizagem desta disciplina. Para tanto, o professor que atua na formação de professores deve discutir com eles o conteúdo e os objetivos a que se destina a formação continuada, porque, do contrário, teremos o que se pode chamar de "pacotes" de cursos, que pouco têm contribuído com a melhoria da qualidade da ação docente em sala de aula.

A Proposta Curricular da EJA destaca que

a aquisi ção de novos conhecimentos deve considerar os conhecimentos prévios dos alunos. (...) , éprimordial partir dos conceitos decorrentes de suas vivências, suas interações sociais e sua experiência pessoal (BRASI L, 2002, p. 15-17).

A mesma proposta chama a atenção para a necessidade de um tratamento respeitoso com os conhecimentos matemáticos que os alunos possuem, conforme destaca Fonseca (2001; 2002).

U m tratamento respeitoso aos conhecimentos que os alunos possuem ocorre quando o professor consegue auscultar, nas falas e nos registros de representação por eles utilizados, as noções matemáticas que já possuem; as reminiscências de que nos fala Fonseca (2001; 2002); o tempo de aprendizagem dos alunos; a complexidade do conceito em discussão; o modo de os alunos se relacionarem com a matemática; e, as vivências e experiências que os alunos possuem. 0 professor precisa, também, perceber as conexões ou relações entre as noções matemáticas que os alunos usam e conhecem fora da escola e os conceitos matemáticos escolares. $\mathrm{N}$ ão basta o professor de matemática ser um bom matemático. Ele precisa, sim, deter profundos conhecimentos matemáticos, ter sensibilidade e tato no trato com os alunos e o ensino. 
O espaço da formação de professores, inicial ou continuada, é um espaço fértil para se refletir sobre tais relações. I sso exige dos formadores de professores uma tomada de posição diante do processo de construção de conhecimentos matemáticos por parte dos alunos e as implicações didáticas dele decorrentes.

0 cenário da formação de professores que ensinam matemática, especialmente na EJA, aponta para a necessidade de os professores (re)conhecerem os alunos como sujeitos sociais. Isso corrobora com o que já fal amos sobre a necessidade de os professores tomarem como ponto de partida os conhecimentos que os alunos já possuem. I sso significa que, além de não perder de vista os conceitos matemáticos, o professor precisa, igualmente, dar atenção ao processo adotado pelos alunos quando da solução dos problemas e na forma como expressam suas soluções.

\section{Como pesquisador}

A pesquisa que resultou na tese de doutoramento, de que aqui fazemos um recorte, amplia e aprofunda o trabalho realizado por ocasião do mestrado (VIZO L LI, 2001), na qual identificamos os registros de representação semiótica necessários à compreensão conceitual de porcentagem como proporção.

Pesquisadores em Educação M atemática, como Almouloud (2003), Bittar (2003), D amm (1992; 1999; 2003), Freitas (2003), M aranhão e I gliori (2003), N ehring (2001), entre outros, têm desenvolvido pesquisas sobre a forma como se processa a aprendizagem de conhecimentos matemáticos, com base na teoria proposta por D uval (1993; 1995; 2003).

Para esses autores, em matemática, toda a comunicação se estabelece com base nas representações dos objetos a serem estudados. H á consenso entre eles de que os objetos matemáticos são conceitos, propriedades, estruturas e relações que expressam diferentes situações e que, para seu ensino, é preciso levar em consideração as diferentes formas de representação de um mesmo objeto. 
D e acordo com D uval (1993), um objeto matemático não é algo pronto, acabado, mensurável ou fisicamente observável, mas sim, estruturas ou relações que podem expressar diferentes situações; por isso precisa-se considerar as diferentes formas de o representar. M uitas vezes, o professor de matemática lança mão de recursos didáticos demonstrativos, visuais ou manipulativos, que nem sempre auxiliam o aluno a expressar certas situações matematicamente. No entanto, é indispensável que o professor tenha clareza da diversidade de registros de representação semiótica, com seus respectivos tratamentos e conversões, coordenando as transformações entre eles.

Para o autor (1993; 1995; 2003), o tratamento é a transformação de uma representação de partida em uma representação de chegada, dentro de um mesmo registro (DU VAL, 1995, p. 40), e a conversão éa transformação de um sistema de representação semiótica para outro, também semiótica (D U VAL 1993; 1995; 2003). Ela é uma transformação externa ao registro de representação de partida.

0 autor ainda menciona que

as representações semióticas são produções constituídas pelo emprego de signos pertencentes a um sistema de representação as quais têm suas construções próprias de significado efuncionamento (DUVAL, 1993, p. 38).

\section{Elas se caracterizam por}

um sistema particular de signos, a linguagem, escrita al gébrica ou os gráficos cartesianos, e que podem ser convertidas em representações equivalentes dentro de outro sistema semiótico, mas podem apresentar significados diferentes para o sujeito que as utiliza (DUVAL 1995, p. 17).

D uval (1993; 1995) estabeleceu três tipos de perspectivas para o termo representação:

a) Representações mentais - Têm função de objetivação; portanto, são internas e conscientes de cada sujeito, ocorrem em nível de pensamento ou do que se tem em mente, estão no mesmo patamar das concepções prévias que se tem sobre determinados fenômenos ou fatos, ou, ainda, sobre as fantasias criadas 
no mundo da infância. As representações mentais são internas e não conscientes do sujeito. Este apenas as executa, utilizandose de regras, de macetes, de fórmulas ou de esquemas, sem pensar em todos os passos necessários para sua execução.

A noção de representação interna é fundamental porque permite mudar a forma de acordo com o nível de tratamento considerado. Elas "recobrem um conjunto de imagens e, mais globalmente, as concepções que o indivíduo tem sobre um objeto, sobre uma situação ou sobre alguma coisa que está associado" (DUVAL, 1993, p. 38).

b) R epresentações internas ou computacionais - Estão relacionadas ao tratamento e se caracterizam pela execução automática de uma determinada tarefa. Elas traduzem informações externas de um sistema em uma forma que seja possível recuperá-las e combiná-las no interior do sistema. Trata-se de teorias que privilegiam o tratamento em que a noção de representação é concebida como uma representação interna ou computacional. 0 tratamento está ligado à forma como se apresenta determinada informação ou um conceito e não a seu conteúdo.

c) R epresentações semióticas - D ependem das representações mentais e computacionais ao mesmo tempo. Elas realizam sucessivamente as funções de objetivação de e tratamento, sendo que o tratamento não é automático e sim intencional; o que é fundamental para a aprendizagem humana (DU VAL, 1995). As representações semióticas pressupõem que se leve em consideração a existência de diferentes sistemas semióticos, permitindo assim a operação cognitiva de conversão das representações entre os diferentes sistemas semióticos.

M uitas vezes, as representações "mentais" não passam de representações semióticas interiorizadas. As representações mentais úteis ou pertinentes em matemática são sempre representações semióticas interiorizadas em interação com um tratamento de produção externa de representações semióticas (DUVAL, 2003, p. 31).

N o ensino e na pesquisa e, em especial, na educação matemática, temos de ter sempre presente que estamos lidando com 
objetos, na maioria das vezes abstratos; algo que não é manipulável, pronto, acabado ou fisicamente observável e que, portanto, pode ter vários significados. Temos, sim, estruturas ou relações que podem expressar diferentes situações ou fatos que, por consequência, não são acessíveis à percepção, necessitando de uma representação que é a base da comunicação, uma vez que expressa o conhecimento que se tem de um objeto de estudo, constituindo-se, assim, numa expressão escrita.

Gráficos, símbolos, figuras, fórmulas, desenhos, conceitos e outros são representações significativas, uma vez que sua utilização permite a comunicação entre as pessoas e as atividades cognitivas do pensamento, e garante diferentes registros de representação para um mesmo objeto matemático.

Q uando se trabalha com problemas, por exemplo, o fundamental não são os desenhos que podem ser feitos a partir do enunciado, nem mesmo as operações matemáticas envolvidas, mas sim o entendimento possível de se estabelecer entre o enunciado, a representação intermediária e o tratamento matemático, uma vez que este objeto não é claro e acessível como os objetos físicos e, exatamente por isso, seu tratamento depende de uma representação semiótica. Segundo D uval, "as representações (semióticas) não são somente necessárias para fins de comunicação; elas são igualmente essenciais para as atividades cognitivas do pensamento" (1993, p. 38).

Como se vê, as representações semióticas não são apenas exteriorização das representações mentais necessárias para se esta belecer uma comunicação, uma vez que o indivíduo que aprende necessita delas para elaborar o conhecimento, portanto, desempenham as funções de cognição (tratamento, conversão e representação).

Para D uval (2003) , a utilização de vários registros de representação propicia o desenvolvimento do conhecimento humano e possibilita a criação de novos sistemas semióticos, a exemplo da evolução nos sistemas de numeração utilizados pela humanidade no decorrer dos tempos. 0 progresso dos conhecimentos é oriundo da criação e do desenvolvimento de novos e específicos 
sistemas semióticos, resultado do trabalho com vários registros de representação. A criação de novos registros está diretamente relacionada às necessidades da espécie humana. $\mathrm{D}$ aí, as diferentes bases no sistema de numeração, os números fracionários, decimais, a porcentagem e tantas outras criações.

\section{Encaminhamentos metodológicos}

Tendo como pressuposto que a solução de problemas clássicos de proporção-porcentagem por alunos e por professores do curso de EJA comporta elementos do contexto social mais imediato, os quais precisam ser levados em consideração quando do processo de ensino e aprendizagem, estabelecemos os seguintes objetivos: a) identificar os registros de representação semiótica utilizados por professores e alunos do curso de EJA ao solucionarem problemas de proporção-porcentagem; b) identificar os conhecimentos matemáticos que são mobilizados no processo de solução de tais problemas. Para tanto, desenvolvemos quatro estudos.

N o Estudo I, solicitamos que três alunos de $3^{\circ}$ Ciclo de aprendizagem solucionassem individualmente três problemas tomados do pós-teste da pesquisa anterior (VIZO LLI, 2001). A pós a solução, entrevistamos os participantes. O s resultados deste estudo apontaram para soluções ancoradas em situações socioculturais.

Inspirados nos problemas clássicos de proporção-porcentagem (D AM M , 1998), elaboramos sete problemas com o tema "salário" e, no Estudo II, solicitamos que, em entrevista, uma dupla de alunos, também de 3 o Ciclo de aprendizagem de EJA, os solucionasse. $N$ este estudo foram identificados registros de representação com marcas escolares, o que nos levou a realizar 0 Estudo III, este com uma dupla de professores.

N o Estudo III, solicitamos que, em entrevista, os professores que atuam na EJA solucionassem apenas os três primeiros 
problemas apresentados no Estudo II. Foram identificados registros com marcas socioculturais e registros de representação semiótica usuais no processo de escolarização.

O Estudo IV foi desenvolvido com quatro duplas de alunos de 4 o Ciclo de aprendizagem do EJA. Foi solicitado que, em entrevista, os participantes solucionassem os três problemas apresentados no Estudo III. A lém de confirmar as indicações presentes nos estudos anteriores, percebemos que, para solucionar os problemas, os alunos buscaram apoio em situações socioculturais e em situações similares àquelas utilizadas pelos professores quando do processo de ensino e de aprendizagem.

\section{A solução de problemas de proporção- porcentagem}

Ao solucionarem problemas que envolvem conceitos matemáticos, as pessoas estabelecem relações entre os dados e as informações contidos nos enunciados dos problemas, com situações do contexto social, seja por meio do tema ou do assunto que o problema aborda (extra-matemática), seja por meio de valores (matemática - quantidades ou taxas) que lhes fossem mais acessíveis. Esses apoios têm conexão com situações que não são de ordem estrita da matemática, como, por exemplo, o trabalho, o comércio, o salário, a família, a escola; e situações que dizem respeito ao conteúdo matemático envolvido no problema, a exemplo, taxas percentuais múltiplas de $5 \%$ ou $10 \%$, metade, dobro, decomposição de quantidades, problemas resolvidos anteriormente, reminiscências escolares, estimativa, cálculo mental, tentativa e erro.

D e acordo com A cioly-R égnier (1997), pode-se dizer que esses apoios são variáveis culturais, as quais desempenham um papel importante no processo de conceitualização. As significações e as justificativas mudam em função da representação que o sujeito tem ou faz da situação. Fonseca (2001) diz que as 
demandas da vida social extra-escolar, particularmente a da vida profissional, constitui-se numa das condições que favorecem a aprendizagem da matemática. Piconez (2002) acompanha os autores que entendem que 0 ambiente social é determinante nas construções cognitivas dos adultos.

Q uando um aluno busca apoio em situações de seu contexto social mais imediato, o professor precisa saber considerar as variáveis pertinentes ao conteúdo cognitivo e fazer com que 0 aluno as perceba. $N$ ão se trata de negar ou de negligenciar sua forma de fazer e de pensar: pelo contrário, tratase de estimulá-lo e de instigá-lo, para que perceba outras possibilidades. Acreditamos que este deve ser o ponto de partida no processo de ensino e aprendizagem.

Pesquisadores em Educação M atemática na EJA como Carvalho (1995), Franco (2000), Fonseca (2001; 2002) e Piconez (2002), entre outros, concordam que os alunos possuem conhecimentos matemáticos que foram adquiridos em seu contexto social e que são mobilizados para solucionar problemas propostos em sala de aula. D estacam que esses conhecimentos devem ser considerados pelos professores no processo de ensino e de aprendizagem. No entanto, o que percebemos é que muitos dos professores que ensinam matemática têm dificuldades em identificar os conhecimentos que os al unos possuem e a forma como os utilizam para solucionar problemas, assim como em aproveitar estes conhecimentos para propor atividades de sala de aula. Embora nossa trajetória profissional não seja o melhor exemplo, ela é um forte indicativo de que as reflexões sobre o próprio fazer pedagógico auxiliam sobremaneira na formação e na constituição do professor.

$\mathrm{Na}$ EJA é bastante comum os alunos responderem oralmente a uma série de problemas de matemática que são apresentados em sala de aula, mas nem sempre registram suas respostas obedecendo às regras de significado e de funcionamento da linguagem matemática (DUVAL, 1993; 1995). O que impele o professor a fazer uma ausculta nos registros verbais orais e escritos 
pelo aluno, na tentativa de explicitar as relações entre as diferentes formas de conhecimento do objeto em estudo, valorizando ou indicando novas possibilidades de registro.

Algumas vezes, as pessoas estabelecem relação entre os dadose as informações contidos no próprio enunciado do problema, isto é, sem buscar apoio em tema/assunto fora do problema. Independentemente disso, pode-se dizer que as pessoas buscam apoio nos conhecimentos de que já dispõem, principalmente em conhecimentos matemáticos.

O exposto coaduna-se aos resultados de pesquisadores como Acioly-R égnier (1997) ePiconez (2002), segundo os quais as significações e justificativas mudam em função da representação que o sujeito tem ou faz da situação. Trata-se de variáveis culturais que desempenham um papel importante no processo de conceitualização. D e acordo com Fonseca (2001), as demandas da vida social extra-escolar, particularmente a da vida profissional, constituem uma das condições que favo recem a aprendizagem da matemática. Podemos dizer que o ambiente social é um componente determinante nas construções cognitivas dos adultos.

Os participantes da pesquisa fizeram uso principalmente de registros de representação semiótica mistos (combinação de linguagem natural escrita e números) e numérico aritméticos. Q uando instigados ou orientados, fizeram uso da tabela de números proporcionais. Somente um dos participantes (professor) fez uso de uma diversidade maior de registros de representação semiótica. Só não fez uso de registros geométricos e gráficos cartesianos (registro de representação não-discursiva - [DU VAL, 2003]).

U ma das tarefas do professor é considerar que um enunciado pode auxiliar ou não o aluno no processo de compreensão conceitual, daí a necessidade da utilização de vários registros de representação para um mesmo objeto matemático e estabelecer a conversão entre eles. N o processo de conversão, é importante que se dê atenção à coordenação, porque é na passagem de um registro de representação para outro que podemos identificar os conhecimentos que são mobilizados no processo de solução. 
A compreensão que se tem sobre um dado registro de representação permite que se atribua o sentido e o significado quando da solução de um dado problema. N o entanto, quando esta compreensão é parcial, não se tem a atribuição de um tratamento matemático de ordem estrita; daí a necessidade da busca de apoio em outras situações, tanto em relação ao tema/assunto como em relação ao objeto matemático. Independente disso, são estraté gias que visam elucidar aspectos do conteúdo cognitivo e tratar matematicamente os dados e as informações.

Em algumas ocasiões, os registros de representação utilizados pelos participantes não foram suficientes para esclarecer os conhecimentos mobilizados, principalmente quando se tratava de representações semióticas já internalizadas. N este caso, 0 registro verbal oral forneceu elementos que nos permitiram saber um pouco mais sobre a forma como os participantes pensavam para solucionar o problema e a compreensão que demonstraram sobre o registro efetuado. Isso nos levou a considerar a fala como um instrumento de mediação entre o participante e o pesquisador, entre os participantes e os registros por eles utilizados e entre o pesquisador e o registro efetuado pelo participante.

Por meio da fala, os participantes foram levados a pensar sobre o pensado, a falar sobre o pensado, a pensar e falar sobre 0 registrado. 0 pesquisador foi levado a auscultar o registrado, 0 falado e a inferir sobre o pensado do participante. Esta situação deveria ser uma prática permanente no processo de ensino e aprendizagem.

E mbora os alunos tenham utilizado uma série de conceitos que formam o substrato para a compreensão do conceito da proporção-porcentagem, o fato de terem lançado mão principalmente de registros de representação semiótica mistos e numérico aritméticos não nos autoriza a afirmar que os alunos compreendem em nível conceitual a proporção-porcentagem. Em determinados momentos, nem mesmo os professores conseguiram perceber as idéias matemáticas que a proporção-porcentagem comporta. 
D urante o processo de solução dos problemas ficou patente, principalmente com os alunos, o uso de registros numéricoaritméticos com tratamentos inerentes às operações fundamentais. Somente os professores e alguns alunos do Estudo IV fizeram uso da regra de três. Para os alunos, o uso desta regra, assim como encontrar o valor correspondente à unidade percentual, não passava de uma forma ou de um método para solucionar os problemas. D ificilmente conseguiam estabelecer as devidas relações entre as quantidades e a taxa percentual, isto é, reconhecer a proporção.

Esse panorama nos permite considerar que os modos utilizados por professores e alunos de EJA ao solucionarem problemas de proporção-porcentagem expressam os conhecimentos que eles possuem sobre o objeto matemático. Tomando como base os princípios da teoria dos registros de representação semiótica, podemos dizer que os alunos possuem compreensão parcial do conceito de proporção-porcentagem, assim como um dos professores.

Os alunos procuraram utilizar formas que Ihes permitissem atribuir um significado operatório ao problema proposto, as quais, nos termos de D uval (1993), podem ser vistas como representações intermediárias entre o registro de representação de partida e de chegada.

Sob o entendimento de que o trabal ho de investigação dos professores pode Ihes auxiliar na elaboração e na proposição de atividades que possibilitam aos alunos ampliarem seus conhecimentos de forma mais articulada, sugerimos enfaticamente que o professor se torne um investigador de sua própria prática pedagógica. Para além do conhecimento do contexto cultural dos alunos, o professor precisa conhecer com profundidade os conteúdos matemáticos e ter subsídios teóricos e metodológicos que deem sustentação para seu fazer em sala de aula. 


\section{Referências}

ACIOLY-RÉ GN IER, N . A justa medida: U m estudo sobre as competências matemática de trabalhadores da cana-de-açúcar no domínio da medida. In: SCH LIEM AN N, A. D. et al. Estudos em psicologia da educação M atemática. 2ª ed. R ecife: U FPE, p. 108-137, 1997.

AL M O U L O U D, S. A. R egistros de R epresentação Semiótica e compreensão de conceitos G eométricos. In: M ACH AD O, S. D. A. (O rg.). A prendizagem em matemática: registros de representação semiótica. Campinas, SP: Papirus, p. 35-48, 2003.

BRASIL (2002). D iretrizesC urricularesN acionaispara EducaçãodeJ ovense A dultos- EJA . São Paulo: A ção Educativa. D isponível em: http://www.açao educativa.org.br/dowloads/parecerp.pdf. A cesso em 15 ago. 2005.

BITTAR , M . $O$ ensino de vetores e os registros de representação semiótical n: M ACH AD O, S. D. A. (O rg.). A prendizagem em matemática: registros de representação semiótica. Campinas, SP: Papirus, p. 35-48, 2003.

CARVALH O, D . L de. (1995). A interação entre o con hecimento matemático da prática eoescolar. Campinas, SP: U N ICAM P. (Tese de D outorado)

DAM M W. L. (1998). Lesproblemesde pourcentage: une application des problèmes de conversion proportion-quantité. A nnales de D idactique et de Sciences Cognitives. Strasbourg: IR EM , 6, p. 197-212.

DAM M , R F. (1992). A pprentissage des prblèmes additifs et compréhesion detexte. Strabourg: U LP. (Tese de D outoramento).

. R egistros de representação. In: M ACH AD O, S. A. D . (O rg.). Educação matemática: uma introdução. São Paulo: E D U C, p 135-154, 1999.

. R epresentação, compreensão e resolução de problemas aditivos. In: MA A CH AD O, S. D . A. (O rg.). A prendizagem em matemática: registros de representação semiótica. Campinas, SP: Papirus, p. 35-48, 2003.

DUVAL, R. R egistres de représentation sémiotique et fonctionnements cognitif dela pensée. In: A nnalesdedidactiqueet SciencesC ognitives. Strasbourg: IREM-ULP, vol.5, p. 37-65, 1993. 
(1995). Sémi osiset pensée humaine: registres sémiotiqueset apprentissages intellectuels. Bern, Berlin, Frankfurt/M . N ew York, Paris, Wien: Peter L ang, editions scientifiques européennes.

- R egistros de representações semióticas efuncionamento cognitivo da compreensão em matemática. In: M ACH A D O, S. A. D . (O rg.). A prendizagem em matemática: regi stros derepresentação semiótica. C ampinas, SP: Papirus, p. 11-34, 2003. (Coleção Papirus Educação).

FO N SECA, M . da C. F. R . (2001). D iscurso, memória einclusão: reminis cências da matemática escolar dealunosadultos do ensinofundamental. Campinas, SP: FE/U N ICAM P. (Tese de doutorado).

. Educação matemática de jovens e adultos especificidades, desafios e contribuições. Belo H orizonte: Autêntica, 2002. (Tendências em educação matemática; 5).

(2004). A educação matemática e a ampliação das demandas de leitura e escrita da população brasileira. In: FO N SECA, M da C. F. R. (O rg). L etramento no Brasil: $\mathrm{H}$ abilidades M atemáticas: reflexões a partir do IN AF 2002. São Paulo: Global, p. 11-28, 2004. A ção Educativa Assessoria, Pesquisa e Informação: Instituto Paulo M ontenegro.

FR AN CO, S. R . K . (2000). A s construções cognitivas do adulto e suas repercussões no processo educativo. In: 23a AN PED. Caxambu, M G. D isponível em: <http//www.anped.org.br/23/textos/1810t.PD F > Acesso em 05 set. 2005.

FR EIRE, Paulo. A educaçãona cidade. São Paulo: Cortez, 1991.

FREITAS, J. L. M. R egistros de R epresentação na produção de provas na passagem da A ritmética para a Álgebra. In: M ACH AD O, S. D. A. (O rg.). A pren dizagem em matemática: registros de representação semiótica. Campinas: Papirus, p. 35-48, 2003. (Coleção Papirus Educação).

GIAR D IN ETTO, J. R. B. M atemática escolar e matemática da vida cotidiana. Campinas, SP: Autores associados, 1999. (Coleção polêmicas do nosso tempo)

KN IJ N IK, G. Exdusão e resistência: E ducação M atemática e legitimidade cultural. Porto Alegre: Artes M édicas, 1996. 
M ARAN H ÃO, M. C. A.; IGLIOR I, S. B. C. (Registros de representação e números racionais. In: M ACH AD O, S. D . A. (O rg.). A prendizagem em matemática: registros de representação semiótica. Campinas, SP: Papirus, p. 35-48, 2003. (Coleção Papirus Educação).

N EH R IN G , C. M . (2001). C omprensão detexto: Enunciados de problemas multiplicativos elementares de combinatória. Florianópolis: U FSC, 2001. (Tese de D outorado em Educação)

PICONEZ, E. C. B. Educação escolar dejovenseadultos Campinas, SP: Papirus, 2002.

POLYA, G. A arte de resolver problemas. um novo aspecto do método matemático. R io de Janeiro: Interciência, 1975.

SANTA CATARIN A, SECRETARIA DE ESTADO DA EDU CAÇÃO, CIÊN CIA E TECN O L O GIA. (2005). Proposta C urricular da Santa C atarina: Estudos Temáticos. Florianópolis: IOESC.

SILVA, J. A . de M. Educação M atemática \& exclusão social: tratamento diferenciado para realidades desiguais. B rasília: Plano Editora, 2002.

SPIN I L LO, A. G. Estratégias na resolução de tarefas de proporção por crianças. In: L ivro de resumos - Semana de Estudos em Psicologia da E ducação M atemática. R ecife, p. 14-18, 1995.

V IZ O L L I, I demar. (2001). R egistro de representação semiótica no estudo deporcentagem. Florianópolis: U FSC. (D issertação deM estrado. M estrado em Educação - Linha de Investigação: Educação e Ciência).

. (2006). R egistros de alunos e professores de E ducação de J ovens e A dultosna solu ção de problemas de propor ção-porcentagem. Curitiba: U PR . (Tese de D outoramento). 